24. Singh, G., Salinity-related desertification and management strategies: Indian experience. Land Degrad. Dev., 2009, 20(4), 367385; doi:10.1002/1dr.933.

25. Maji, A. K., Reddy, G. P. O. and Sarkar, D., Degraded and wastelands of India: status and spatial distribution. Directorate of Information and Publications of Agriculture, Indian Council of Agricultural Research, New Delhi and National Academy of Agricultural Sciences, New Delhi, 2010, p. 158.

26. Budihal, S. L. et al., Assessment and mapping of desertification status in Bellary district, Karnataka State, using IRS data. In ISPRS Commission IV International Symposium on Geospatial Databases for Sustainable Development, Goa, 25-30 September 2006.

27. Reddy, R. S., Nalatwadmath, S. K. and Krishnan, P., Soil erosion in Andhra Pradesh. National Bureau of Soil Survey and Land Use Planning, Publication No. 114, NBSSLUP, Nagpur, 2005, p. 76.

28. Naidu, L. G. K. et al., Evaluation of soil and climatic characteristics for identifying constraints and potentials for forest development in Andhra Pradesh, India. Indian J. Dryland Agric. Res. Dev., 2017, 32(1), 63-70; doi:10.5958/2231-6701.2017.00011.2.

Received 2 January 2018; revised accepted 8 March 2018

\section{Integrated assessment of drought vulnerability using indicators for Dhasan basin in Bundelkhand region, Madhya Pradesh, India}

\author{
Saswat Kumar Kar ${ }^{1, *}$, T. Thomas ${ }^{2}$, R. M. Singh ${ }^{1}$ \\ and Lokesh Patel ${ }^{2}$ \\ ${ }^{1}$ Department of Farm Engineering, Institute of Agricultural Sciences, \\ Banaras Hindu University, Varanasi 221005 , India \\ ${ }^{2}$ Ganga Plains South Regional Centre, National Institute of Hydrology, \\ Bhopal 462 016, India
}

The present study has integrated both spatially and temporally varying drought vulnerability factors to develop an integrated drought vulnerability map for Dhasan basin. A drought vulnerability index is used to classify the study area into different vulnerability zones. From the drought vulnerability assessment for the study area during July 2002, it was observed that the northeast, northwest and extreme southern part of the basin (20\% area) was under critical vulnerability condition whereas the southwest and central part of the basin $(79.9 \%$ area) was under high vulnerability condition. The critical drought vulnerability condition existed in Dhamoni, Pidaruwa, Sagar, Patharia Hat, Chhapri, Baroda Sagar and Singtoni region, whereas high vulnerability condition

*For correspondence. (e-mail: saswatkumarkar@gmail.com) existed in the remaining parts of the study area. The integrated drought vulnerability approach gives superior result for drought assessment as compared to vulnerability assessment by considering the individual factors for the study area.

Keywords: Drought characteristics, drought indicators, drought vulnerability.

DROUGHT is a climatic hazard and a major threat among the natural climatic hazards to livelihood and socioeconomic development of people. Drought may be defined as the scanty availability of water resulting due to subnormal or erratic rainfall distribution, or a combination of both factors for a long period ${ }^{1}$. However, it affects a wide region for a season or for consecutive years. The arid areas are more vulnerable to drought as their source of rainfall depends on few rainfall events ${ }^{2}$. The ascent of drought is due to late arrival of rains, early withdrawal of monsoon, light rainfall, lack of sufficient soil moisture leading to crop failure and migration of local population. Water shortages due to the failure of the southwest monsoon lead to several situations like crop loss, less crop yields or agricultural drought. The areas under severe drought advance gradually and regions under maximum drought intensity vary from season to season ${ }^{3}$. The parameters indicating drought impacts comprise soil moisture depletion, reduction in streamflow, reservoir storage, lake levels and groundwater level ${ }^{1}$. Several methodologies have been recommended for studying the characteristics of drought to support policy makers in addressing this complex event. However, drought severity is the key factor to decide characteristics of drought. Drought severity is assessed by drought indices, which are indicator based and useful for identifying and monitoring drought precisely ${ }^{4}$. The drought period has considerable environmental, agricultural, health, economic and social consequences which vary according to susceptibility. Marginal farmers are more affected and drift during drought as they do not have substitute food sources.

Vulnerability assessment is the most significant aspect of drought hazard assessment and in development of drought management plans. Assessment of climate change vulnerable regions will help in the scientific understanding of climate sensitive parameters and aid in developing policies to reduce risks and prioritize research efforts in vulnerable regions to develop mitigation and adaptation strategies ${ }^{5}$. The drought vulnerability of wheat farmers was studied using Me-Bar and Valdez's vulnerability formula which revealed that vulnerability is a function of economic, socio-cultural, psychological, technical and infrastructural factors and there is a significant relationship between the agricultural income of the farmer and drought vulnerability ${ }^{6}$. Agricultural drought vulnerability for Nebraska state of central United States was studied based on factors such as climate, soils, land use and 
irrigation facility and the drought vulnerability map was prepared to visualize the level of hazard ${ }^{7}$. An integrated assessment of drought vulnerability of small farm holders was carried out in Ceara region of Brazil by considering three components like exposure, sensitivity and adaptive capacity and the range of drought vulnerability factor is from zero to one ${ }^{8}$. The closer is the factor to one, the higher is the vulnerability for the region. The vulnerability to climate change of various states of India was studied, using the Vulnerability Resilience Indicator Prototype (VRIP) ${ }^{9}$. It calculates indicators of sensitivity, coping and adaptive capacity to climate change and aggregates them into a single indicator of vulnerability index. The nature of vulnerability to agricultural drought was analysed in three blocks of Bolangir district in western Orissa and three most influential biophysical factors of drought vulnerability were identified, viz. rainfall variability, drought intensity and shortage of soil moisture; the three most valuable socioeconomic factors are: smaller forest area, less irrigation development and poor crop insurance ${ }^{10}$. This methodology is found suitable for integrating both quantitative and qualitative characteristics of drought vulnerability at different spatial scales.

A new methodology called inference modelling approach was developed to compare and analyse various qualitative indicators such as economics, political science and environmental psychology which were converted into quantitative indicators by using fuzzy set theory for estimation of drought vulnerability ${ }^{11}$. The social vulnerability to drought was estimated by considering the components of vulnerability index such as natural resource, economic capacity, human and civic resources, and agricultural innovation with their respective representative variables having an appropriate weight and the overall vulnerability was determined by taking the weighted average of each of the four components ${ }^{12}$. Both the hydro-meteorological and physiographic factors were used for assessment of drought vulnerability in the Sonar basin (Madhya Pradesh) and findings of the study suggest that the vulnerability depends on water demand, topographical features, soil type, land use land cover and groundwater resource exploitation in the region ${ }^{13}$. An integrated drought vulnerability assessment was carried out based on multiple spatial and temporal factors using ILWIS 3.0 for Bearma basin in Bundelkhand region of central India ${ }^{14}$. In the present study, an attempt has been made to address the drought vulnerability of the Dhasan basin situated in Bundelkhand region of central India. For this purpose various spatially and temporally varying factors have been taken into consideration. The spatial indicators, which do not fluctuate with each drought event include topographic features, soil characteristics and land use pattern whereas, the temporal indicators which vary during every drought event consist of rainfall departures, soil moisture availability, surface water availability and groundwater availability. A drought vulnera- bility map was prepared for the basin by integrating all the drought indicators based on the weighing scheme.

In this paper, quantification and assessment of drought vulnerability of the Dhasan basin in Bundelkhand region which has been facing climatic extremes like drought since the last few decades was carried out to understand the drought scenario. Various types of droughts including meteorological drought, soil moisture drought, streamflow drought, groundwater drought were analysed using appropriate drought indicators. A new methodology has been proposed in this study wherein the spatially and temporally varying drought vulnerability factors have been incorporated to arrive at an integrated drought vulnerability map of the study area.

The study area was limited to the Dhasan basin up to Patan village in the drought-prone region of Bundelkhand (Madhya Pradesh), with a catchment area of 2054.39 sq. $\mathrm{km}$, and it is extended between $23^{\circ} 28^{\prime} 56^{\prime \prime} \mathrm{N}$ to $24^{\circ} 16^{\prime} 20^{\prime \prime} \mathrm{N}$ lat. and $78^{\circ} 23^{\prime} 24^{\prime \prime} \mathrm{E}$ to $78^{\circ} 57^{\prime} 03^{\prime \prime} \mathrm{E}$ long. River Dhasan joins river Betwa which is a tributary of the Yamuna river system. The daily rainfall data at three rain gauge stations, viz. Sagar, Banda and Khurai located in and around the basin were collected for the period spanning from 1980 to 2009. The average maximum, minimum and mean daily temperatures for Sagar district are $45.6^{\circ} \mathrm{C}, 1.1^{\circ} \mathrm{C}$ and $23.3^{\circ} \mathrm{C}$ respectively. Hydrologically, the entire study area is comprised of hard rock formations. The scarcity of water for drinking as well as irrigation purpose is the main problem in the Dhasan basin. Agriculture which is mostly rainfed is the main livelihood of the farmers in the region. Maize, soybean, oilseeds, sorghum, etc. are the major crops cultivated during $\mathrm{Kha}$ rif season and wheat, pulses, chickpea, etc. are cultivated during Rabi season.

Generally, monsoon season commences between 15 and 30 June and lasts for 3-4 succeeding months. Maximum rainfall is obtained during August followed by July. More than $90 \%$ of the annual rainfall is delivered by the southwest monsoon during June-September and the rest during winter and summer seasons. The average aerial rainfall for the study area was computed using the Thiessen polygon method in ILWIS 3.0, a Geographic Information System (GIS) software. For estimation of basin average rainfall initially, a base map of the basin, as well as a point map showing the location of the three rain gauge stations was prepared. Later, the nearest point algorithm was applied for interpolation. The resultant map was crossed with the base map in raster operation to get the Thiessen polygon map of the study area. The resultant histogram has been used to compute the Thiessen weights of the influencing rain gauge stations. The average annual rainfall of the Dhasan basin is around $1117.2 \mathrm{~mm}$ and seasonal rainfall is about $1020.2 \mathrm{~mm}$.

Rainfall departure is a decisive indicator of dry or wet conditions for a given time over definite areas. The evaluation of meteorological drought severity was carried out 
by employing IMD method ${ }^{15}$. The drought years have been identified based on the departure analysis of annual and seasonal rainfall for the study period. The annual or seasonal rainfall departure was figured out by subtracting the mean of annual or seasonal rainfall $\left(R_{\mathrm{m}}\right)$ from the annual or seasonal rainfall $\left(R_{\mathrm{i}}\right)$ for that year respectively. The percentage departure $\left(D_{\mathrm{i}}\right)$ is subsequently computed by dividing the mean rainfall for the station by the rainfall departure as given by eq. (1).

$$
D_{\mathrm{i}}(\%)=\frac{\left(R_{\mathrm{i}}-R_{\mathrm{m}}\right)}{R_{\mathrm{m}}} \times 100,
$$

where $D_{\mathrm{i}}$ is the annual or seasonal rainfall departure for the $i$ th year; $R_{\mathrm{i}}$ the annual or seasonal rainfall for $i$ th year and $R_{\mathrm{m}}$ is the average annual or seasonal rainfall for the period of study.

The departure analysis of annual and seasonal rainfall has been performed for the influencing rain gauges, viz. Sagar, Banda and Khurai and subsequently the drought years were identified. Based on the rainfall departure ranges $10-20 \%, 20-25 \%, 25-50 \%$ and more than $50 \%$, the drought was classified into four severity classes as mild, moderate, severe and extreme respectively.

The Standardized Precipitation Index (SPI) is used for drought monitoring and analysis ${ }^{16}$. The SPI was computed for three timescales, viz. 3-month time scale denoted by $3 \mathrm{~m}$-SPI, 6 -month time scale represented by $6 \mathrm{~m}$-SPI, and 12 -month time scale symbolized by $12 \mathrm{~m}$-SPI for which a program was compiled using Fortran 90. The computation of SPI requires continuous long-term data of monthly precipitation for at least 30 years. The classification of drought severity is based on the SPI range; if the SPI value lies between -1.00 and -1.49 , it indicates moderate drought situation; similarly the SPI range between -1.50 and -1.99 , denotes severe drought condition and the SPI value less than -2.00 , leads to an extreme drought state. The computation of the SPI involves the following steps: (1) calculation of mean of the normalized precipitation of the log-normal (ln) rainfall series; (2) fitting a two-parameter gamma probability density function to a given frequency distribution of the precipitation; (3) computation of shape and scale parameters $\beta$ and $\alpha$ respectively for each time scale of interest $(3,6$ and 12 months).

For land use land cover (LULC) classification satellite imagery Landsat-7 (ETM +) was used which was obtained from open source U.S.Geological Survey online service with a spatial resolution of $30 \mathrm{~m}$. The image package has several bands including a separate band for resolution merge. Layer stack process was applied using ERDAS Imagine 2011 software by combining bands, to make the image ready for use and to prepare RGB false colour composite image and resolution merge for a blur free image. It was followed by mosaic operation under the raster menu. Further, the study area was obtained by sub-setting and clip operation. After making the image ready for use, an unsupervized classification tool was used to classify different land use land cover categories based on their reflectance values. Eight classes were identified, viz. agricultural land, fallow land, water bodies, habitation, dense forest, scrub forest, land with or without scrub and barren rocky. To carry out further analyses, vectorization of these classes was done. The vectorization process was carried out through a conversion tool in ArcMap software. By vectorization, each LULC class was converted into polygons so that the area calculations and other report generation processes were made easy. The area under cultivable land is maximum, followed by dense forests.

The soil map of Madhya Pradesh was collected from the ICAR-National Bureau of Soil Survey and Land Use Planning, Nagpur at a scale of $1: 5,00,000$. As the study area fell in sheets 4 and 5, these sheets were georeferenced and the boundary of each soil group was digitized with the help of ArcGIS 9.3 and the soil map showing eight classes as per USDA system of soil classification was prepared. Eight soil groups were identified in the study area namely, deep clayey, deep calcareous clayey, moderately deep calcareous clayey, slightly deep clayey, very shallow clayey-skeletal, deep loamy, slightly deep loamy and very shallow loamy. Most of the area was covered by deep calcareous clayey type soils.

The digital elevation model (DEM) data for the study area was downloaded from SRTM data version 4.1 in GeoTIFF having $90 \mathrm{~m}$ resolution for column 52 and row 08. The SRTM data were resampled using ILWIS 3.0 and reclassified into three elevation ranges namely, lower reach (elevation less than $475 \mathrm{~m}$ ); middle reach (elevation between 475 and $550 \mathrm{~m}$ ) and upper reach (elevation more than $550 \mathrm{~m}$ ). The upper reach portion of the basin is sloppy; so there is less water retention time as water flows out suddenly. However, the middle and lower reach portions have comparatively more time for water to infiltrate. Therefore, the upper reach followed by middle reach and lower reach is more vulnerable to the occurrence of drought.

Soil moisture is an important parameter controlling the incidence of agricultural drought in an area and lack of soil moisture in the plant root zone develops a water deficit condition for crop growth. Hence the reduction in soil moisture is an indicator of vulnerability towards drought. Considering the non-availability of spatially and temporally varying soil moisture data for the Dhasan basin, the $3 \mathrm{~m}$-SPI has been substituted as a suitable indicator to signify the soil moisture variation as observed from literature review ${ }^{14,17}$. The $3 \mathrm{~m}$-SPI values for each of the monsoon months of the identified drought years have been spatially interpolated using ILWIS 3.0 and grouped into severity classes to obtain the variation of the drought severity in the basin. 
Hydrological droughts occur due to prolonged dry spells and meteorological drought. It consists of three components namely, surface water drought, groundwater drought and deficits in reservoir storage. Presently, there are no water harvesting structures like check dams, reservoirs etc. in the study area, and therefore only surface water and groundwater drought characteristics have been analysed.

As there are no gauging sites for the measurement of stream flow anywhere in the study area, based on literature survey, alternate indices have been used to represent the surface water drought in the study area ${ }^{14}$. The $6 \mathrm{~m}$-SPI has been used to characterize the surface water drought in the Dhasan basin up to Patan. The 6m-SPI values of all the rain gauge stations for each of the monsoon months during the identified drought years have been spatially interpolated and reclassified into four drought classes to represent the variation of drought severity in the basin.

Groundwater availability is an important parameter in deciding the drought severity of an area. Lack of groundwater in the aquifer causes decline in water table which ultimately affects the water supply for domestic as well as agricultural use thus making the region vulnerable to drought. The groundwater level data are required on a monthly basis for estimation of groundwater drought, whereas the data are available on a quarterly basis for the months of August, November, January and May in the study area. Due to the absence of monthly GDI values and based on literature review, the groundwater drought characteristics have been evaluated using the $12 \mathrm{~m}$-SPI ${ }^{18}$. The $12 \mathrm{~m}$-SPI values for each monsoon month during the identified drought years have been spatially interpolated and reclassified into drought severity classes to understand the spatial and temporal variation of drought severity within the basin.

Multiple drought indicator approaches have been used for identifying the drought-vulnerable zones in the Dhasan basin instead of deciding the drought situation based on a single parameter. The spatial and temporal variations in drought characteristics have been evaluated using the two most important components namely, spatially varying factors and both spatially and temporally varying factors. The multiple factors used include topographic features of the basin, soil type, land use land cover pattern, rainfall departure, soil moisture availability, streamflow availability and groundwater availability.

Each drought indicator is grouped into several subclasses based on its exposure to drought and a numerical weight varying between 0 and 5 is assigned to each subclass according to the susceptibility. An upper value of weight (5) for any sub-class of an indicator shows that it is highly vulnerable to drought due to its least susceptibility. On the other hand a lower weight (0) indicates less vulnerability to drought due to its high susceptibility. So, zero is considered the least vulnerable situation and 5 is the most vulnerable condition. The weighing scheme for the drought vulnerability classification is given in Table 1.

Integrated drought vulnerability assessment is based on the integration of all these spatially and temporally varying factors. For this purpose, the sum of weights of seven vulnerability factors has been transformed into a new drought vulnerability index (DVI) ${ }^{13,14}$. The DVI may be defined as the ratio of the sum of weights of drought vulnerability indicators to the maximum weight of the vulnerability indicator times total number of indicators considered. The DVI may be described as given below in eq. (2)

$$
D V I=\frac{\sum W_{i}}{k \times N},
$$

where DVI is the drought vulnerability index; $N$, the number of spatial and temporal factors under consideration; $W_{i}$, the weights of drought vulnerability indicators (where $i=1,2, \ldots, 7$ ) and $k$ is the maximum value of vulnerability weights.

For the proposed methodology, various spatial and temporal maps were prepared at a uniform grid of resolution $50 \mathrm{~m} \times 50 \mathrm{~m}$. The combined map was prepared by the addition of various layers to arrive at the basic integrated drought vulnerability map of the basin after which DVI was computed. Higher DVI value indicates high vulnerability towards drought and low DVI indicates less vulnerability. The study area was classified into five vulnerability classes with regard to their degree of impact to drought vulnerability, namely critically vulnerable (DVI: 0.8-1.0), highly vulnerable (DVI: 0.6-0.8), moderately vulnerable (DVI: 0.4-0.6), slightly vulnerable (DVI: 0.2-0.4) and least vulnerable (DVI: 0-0.2). The vulnerable areas were identified and the area coming under respective vulnerability classes was estimated.

Various spatially varying drought vulnerability indicators, viz. basin reaches, land use pattern and soil type were evaluated for the study area and the drought prone areas were identified.

The basin was categorized into three elevation zones based on DEM, viz. upper reach, middle reach and lower reach according to flow characteristics in stream sections, stream orders and topographic features (i.e. average slopes). The upper parts of the basin were considered more vulnerable followed by the middle and lower parts. The map showing various basin reaches for the Dhasan basin up to Patan is given in Figure $1 a$. As shown in the figure, during 2002 about $68.5 \%$ (1407.23 sq. km) area fell in middle reach which was moderately vulnerable to drought followed by $18.6 \%$ (381.82 sq. km) area under lower reach which was slightly vulnerable to drought and $12.9 \%$ (265.34 sq. km) area under upper reach was severely vulnerable to drought.

The land use map of the Dhasan basin up to Patan, prepared using ERDAS imagine 2011 is given in Figure $1 b$ 
Table 1. Weighing scheme for drought vulnerability classification

\begin{tabular}{|c|c|c|}
\hline Type of classification & Classification factors & Weights assigned \\
\hline \multirow[t]{3}{*}{ Basin reaches } & Lower & 1 \\
\hline & Middle & 3 \\
\hline & Upper & 5 \\
\hline \multirow[t]{8}{*}{ Land use pattern } & Barren rocky & 0 \\
\hline & Water bodies & 0 \\
\hline & Scrub forest & 1 \\
\hline & Land with or without scrub & 1 \\
\hline & Fallow land & 2 \\
\hline & Dense forest & 3 \\
\hline & Agricultural land & 4 \\
\hline & Habitation & 5 \\
\hline \multirow[t]{8}{*}{ Soil type } & Deep clayey & 0 \\
\hline & Slightly deep clayey & 0 \\
\hline & Deep calcareous clayey & 1 \\
\hline & Moderately deep calcareous clayey & 1 \\
\hline & Very shallow clayey skeletal & 1 \\
\hline & Deep loamy & 2 \\
\hline & Slightly deep loamy & 3 \\
\hline & Very shallow loamy & 4 \\
\hline \multirow[t]{4}{*}{ Monthly rainfall departure } & Mild & 1 \\
\hline & Moderate & 3 \\
\hline & Severe & 4 \\
\hline & Extreme & 5 \\
\hline \multirow[t]{4}{*}{ Soil moisture availability } & Mild & 1 \\
\hline & Moderate & 3 \\
\hline & Severe & 4 \\
\hline & Extreme & 5 \\
\hline \multirow[t]{4}{*}{ Surface water availability } & Mild & 1 \\
\hline & Moderate & 3 \\
\hline & Severe & 4 \\
\hline & Extreme & 5 \\
\hline \multirow[t]{4}{*}{ Ground water availability } & Mild & 1 \\
\hline & Moderate & 3 \\
\hline & Severe & 4 \\
\hline & Extreme & 5 \\
\hline
\end{tabular}

The range for the classification factors are, mild $(-0.50$ to -0.99$)$, moderate $(-1.0$ to -1.49$)$, severe $(-1.50$ to -1.99 ) and extreme (less than -2.0 ).

Table 2. Soil details of the study area

\begin{tabular}{lcc}
\hline Soil type & Area (sq. km) & Area (\%) \\
\hline Deep clayey & 191.53 & 9.32 \\
Slightly deep clayey & 158.03 & 7.69 \\
Deep calcareous clayey & 853.45 & 41.54 \\
Moderately deep calcareous clayey & 215.48 & 10.49 \\
Very shallow clayey-skeletal & 19.94 & 0.97 \\
Deep loamy & 15.77 & 0.77 \\
Slightly deep loamy & 230.18 & 11.20 \\
Very shallow loamy & 370.01 & 18.01 \\
\hline
\end{tabular}

and comprises eight land use classes. The habitation has highest priority water demand for drinking and other domestic purposes than any other land uses. Therefore, the habitation areas which cover an area of $2.2 \%$ were considered to be critically vulnerable. Agricultural lands which cover an area of $27.10 \%$, are considered to be the next highly vulnerable areas due to higher water demand for crop production and any water deficit during the critical growth stage would cause a reduction in yield or loss of crops. Vulnerability to drought in these two areas would lead to food insecurity and migration of local population. Therefore, the agricultural area is more vulnerable when compared to forest areas and other land use types. Due to drought in 2002 , about $37 \%$ of area was fallow land which is the next vulnerable area when compared to dense forests. On the other hand, the barren areas and water bodies which are about $3.1 \%$ of the study area are not considered to be vulnerable to drought as there is no habitation as well as vegetation in such areas.

The soil map of the Dhasan basin up to Patan is given in Figure $1 c$ and the area under the various soil classes is given in Table 2. The vulnerability of a particular type of 

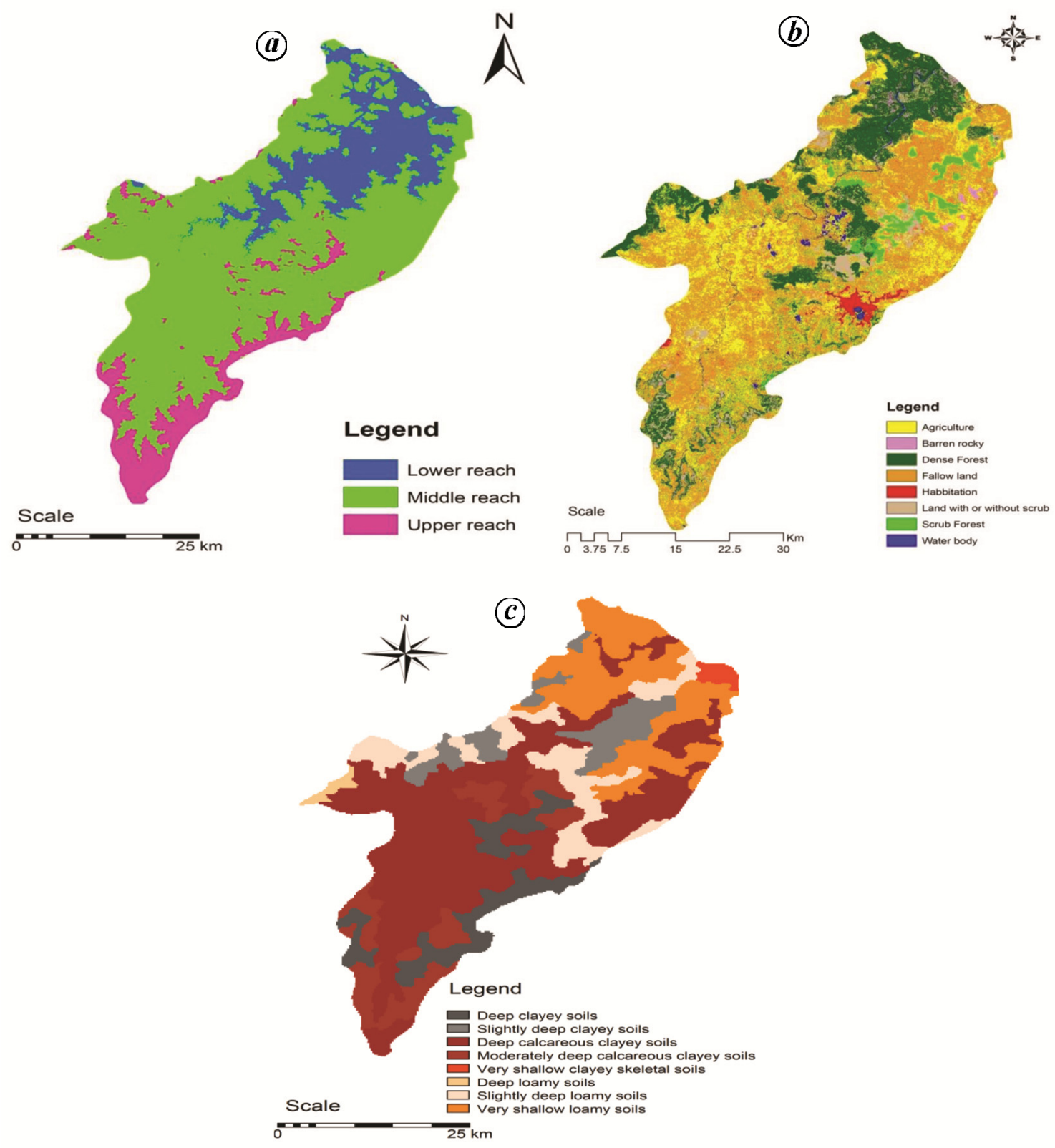

Figure 1. The map of various spatially varying drought vulnerability indicators of Dhasan basin up to Patan. $\boldsymbol{a}$, Basin reach map; $\boldsymbol{b}$, Land use land cover map; $\boldsymbol{c}$, Soil map.

soil to drought depends upon the water holding capacity in its soil pore which varies considerably. Hence heavy textured soils (clayey soil) which retain more water are less vulnerable to drought followed by loamy and sandy light textured soils which are comparatively more vulnerable. Hence the deep calcareous clay soils which cover most parts of the study area $(41.54 \%)$ are considered slightly vulnerable to drought because they retain higher moisture when compared to other types of soils. On the other hand, deep loamy soils have less water retaining capacity and are therefore more vulnerable to drought.

Various temporally varying drought vulnerability indicators, viz. monthly rainfall departure, soil moisture availability, surface water availability and groundwater availability are evaluated for the study area and the drought prone area was identified.

Monthly rainfall departure was calculated for various months of the monsoon season for the identified drought years. Negative rainfall departure is more noticeable during drought years and varies for each drought year under concern. Percentage rainfall departure has been determined to assess drought vulnerability of every month during the monsoon season. The rainfall departure map for June 2002-03, based on the rainfall departure at Sagar, Banda and Khurai is given in Figure $2 a$. The monthly departure analysis map shows that most of the 

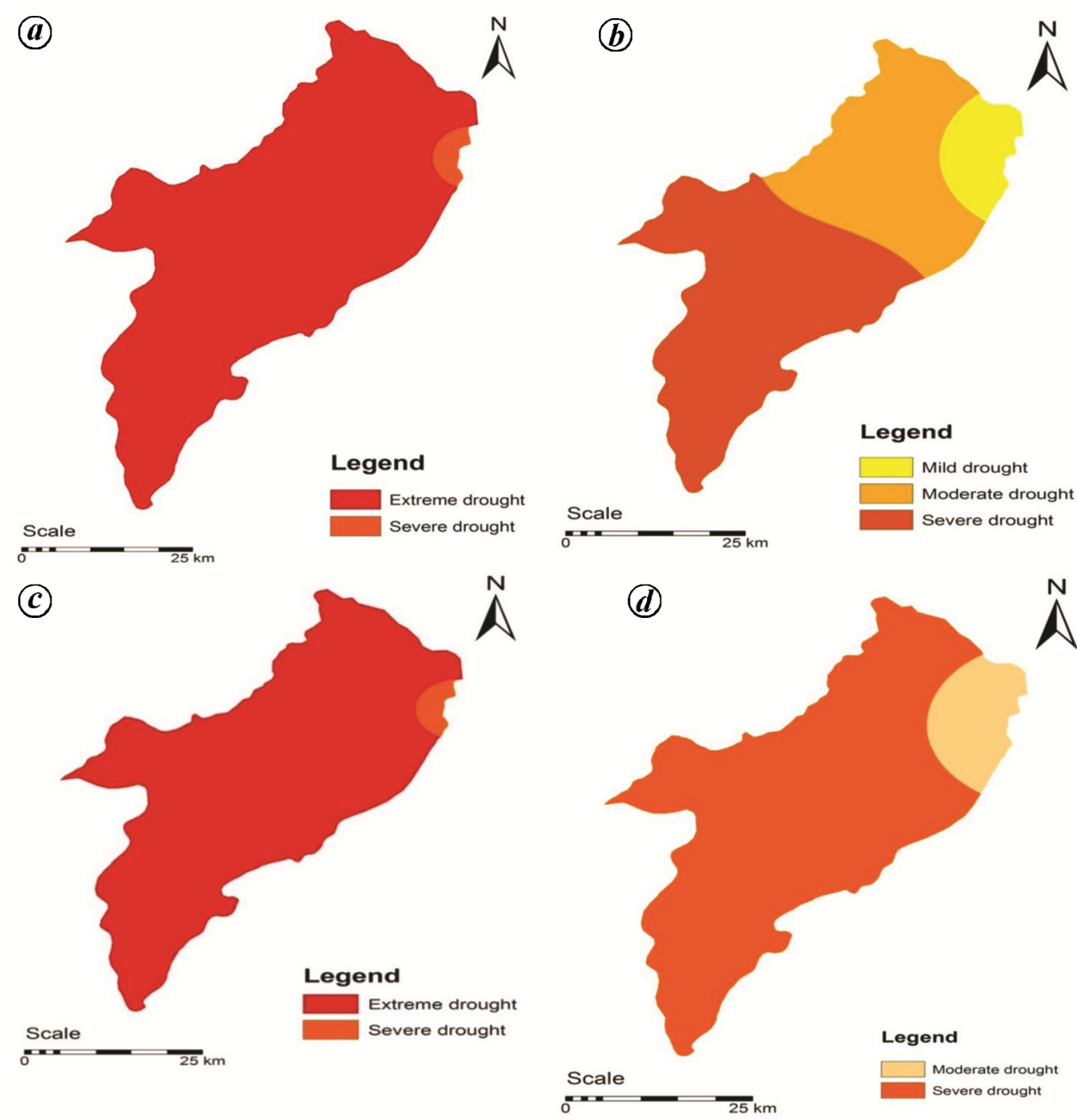

Figure 2. Maps of various temporally varying drought vulnerability indicators. $\boldsymbol{a}$, Rainfall departure map for June 2002$03 ; \boldsymbol{b}$, Soil moisture drought variation during June 2002; $\boldsymbol{c}$, Surface water drought variation during July 2002; $\boldsymbol{d}$, Groundwater drought variation during August 2002.

region $(98.35 \%)$ was under extreme drought and the remaining $1.65 \%$ area was under severe drought condition.

Reduction in the level of soil moisture is a vital factor for causing vulnerability to drought. 3m-SPI was used to recognize soil moisture variability in the basin. Variation of the soil moisture is presented in Figure $2 b$. It was observed that most of the region fell under extreme drought during June 2002.

Lowering of the surface water level or its deficit is an indicator of vulnerability to drought which may cover the flow in small channels, streams, rivers, ponds, tanks, reservoirs and other water bodies. $6 \mathrm{~m}$-SPI was chosen as a suitable indicator to represent the variation of surface water availability in the Dhasan basin up to Patan. Variation of the surface water availability during July 2002 is presented in Figure $2 c$.
In the absence of monthly groundwater drought index values, and based on the literature review, groundwater drought characteristics were evaluated using $12 \mathrm{~m}-\mathrm{SPI}$. The spatial and temporal variation of groundwater drought severity within the basin during August 2002 is shown in Figure $2 d$.

Integrated drought vulnerability maps during JuneSeptember 2002 are given in Figure 3. The area falling under various drought vulnerability classes during 2002 are given in Table 3. In June 2002, about 53.9\% of the study area was under the high vulnerability class, followed by $42.9 \%$ under the moderate vulnerability class; whereas about $3.1 \%$ was under the slight vulnerability class and a small patch of around $0.04 \%$ area was under the critical vulnerability class. The northeast portion of the study area was mostly moderately vulnerable whereas the southern part and some stretches of the western part 

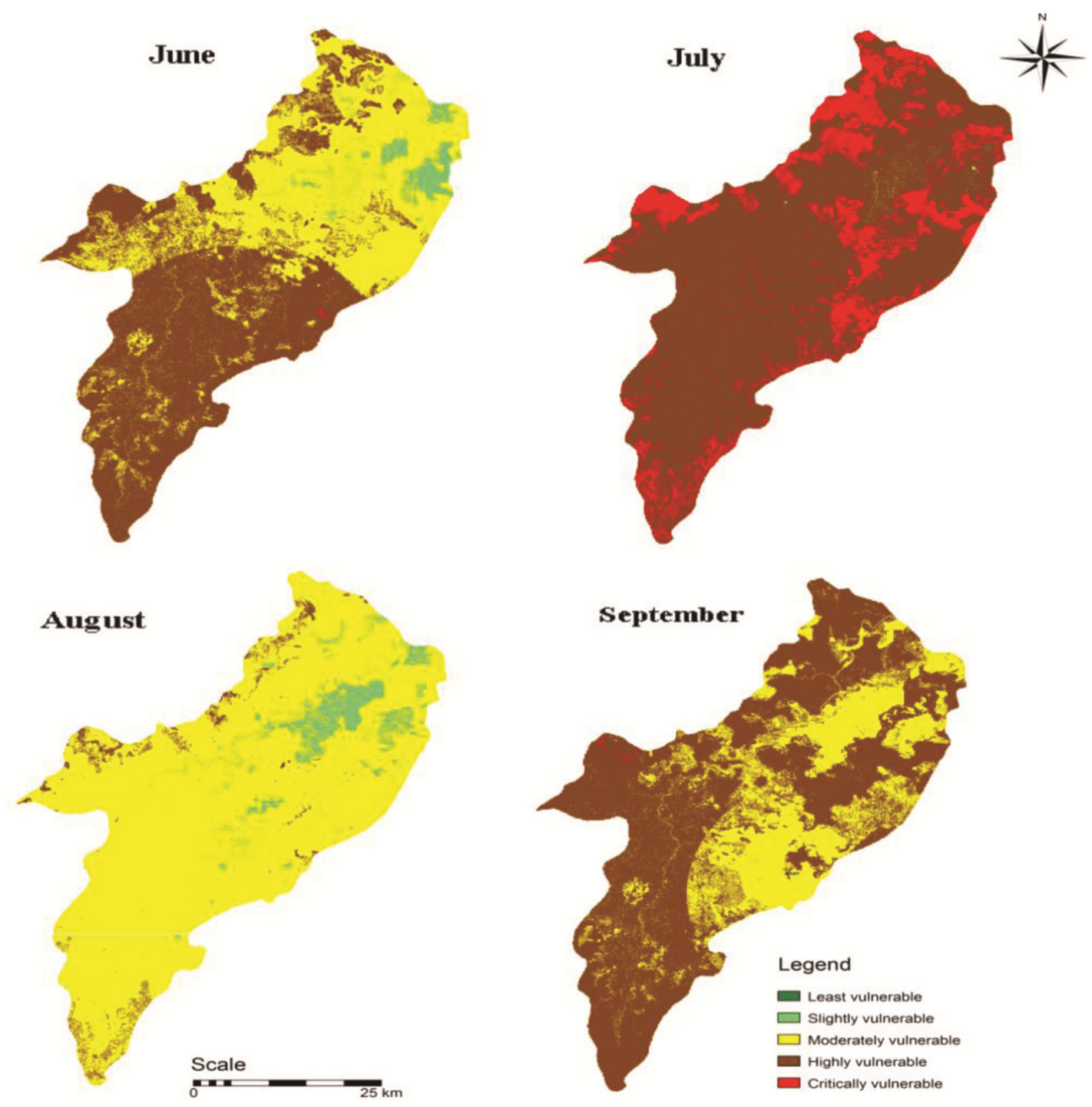

Figure 3. Drought vulnerability map during 2002.

Table 3. Area under various drought vulnerability classes

\begin{tabular}{lllll}
\hline & \multicolumn{3}{c}{ The area under various severity classes (sq. km) } \\
\cline { 2 - 5 } Drought vulnerability & \multicolumn{1}{c}{ June 2002 } & \multicolumn{1}{c}{ July 2002} & \multicolumn{1}{c}{ August 2002 } & \multicolumn{1}{c}{ September 2002 } \\
\hline Not vulnerable & $0.0(0 \%)$ & $0.0(0 \%)$ & $0.0(0 \%)$ & $0.0(0 \%)$ \\
Slightly vulnerable & $64.37(3.13 \%)$ & $0.00(0 \%)$ & $121.25(5.90 \%)$ & $0.23(0.01 \%)$ \\
Moderately vulnerable & $881.76(42.9 \%)$ & $2.66(0.13 \%)$ & $1862.17(90.64 \%)$ & $634.59(30.89 \%)$ \\
Highly vulnerable & $1107.45(53.91 \%)$ & $1640.83(79.87 \%)$ & $70.97(3.45 \%)$ & $1417.58(69.00 \%)$ \\
Critically vulnerable & $0.81(0.04 \%)$ & $410.90(20.00 \%)$ & $0.00(0 \%)$ & $2.00(0.10 \%)$ \\
\hline
\end{tabular}

were highly vulnerable. Slightly vulnerable conditions were found in Singtoni and Banda, whereas moderately vulnerable conditions existed in Bahrol, Magardha, Karrapur and Chhapri. However, severe vulnerable conditions prevailed in Pidaruwa, Baroda Sagar, Patharia Hat, Sagar and Dhamoni. Due to lack of sufficient rainfall during monsoon, the situation worsened considerably in July
2002 , with about $20 \%$ of area coming under the critical vulnerability class, followed by $79.9 \%$ under the high vulnerability class. The northeast, northwest and extreme southern parts of the basin were under the critical vulnerability class whereas the southwest and central part of the basin were under the high vulnerability class. Dhamoni, Pidaruwa, Sagar, Patharia Hat, Chhapri, Baro- 


\section{RESEARCH COMMUNICATIONS}

da Sagar and Singtoni were critically vulnerable, whereas the remaining parts of the study area were highly vulnerable to drought. Towards the end of the monsoon season, during September, the area under the critical vulnerability class reduced to about $0.10 \%$ whereas the area under the high vulnerability class reduced to around $69 \%$, and area under the moderate vulnerability class was around $30.9 \%$. Similar analysis was carried out for the remaining identified drought years (2007-08, 1992-93 and 1988-89) during which extensive droughts were observed in the region. This analysis will help identify vulnerable regions in the basin where the drought frequency is high. Based on this information, proper mitigation strategies can be planned and early drought warning systems can be developed to reduce the impact of drought in vulnerable areas.

The present methodology has integrated both spatially and temporally varying drought vulnerability factors to reach an integrated drought vulnerability map of the study area, instead of drought vulnerability assessment by considering individual factors. The integrated drought vulnerability approach gives superior results for drought assessment compared to any individual factor for the study area. A drought vulnerability index was also used for classification of the study area into different vulnerability zones. From the drought vulnerability assessment of the study area during July 2002, it was observed that the northeast, northwest and extreme southern parts of the basin $(20 \%$ area) were under the critical vulnerability condition, whereas the southwest and central parts of the basin $(79.9 \%$ area) were under the high vulnerability condition. Critically drought vulnerable condition existed in Dhamoni, Pidaruwa, Sagar, Patharia Hat, Chhapri, Baroda Sagar and Singtoni regions, whereas high vulnerability condition existed in the remaining parts of the study area. During the drought years, a considerable portion of the basin fell under the moderate and severe vulnerability classes. This appeals for long-term planning to develop appropriate drought proofing for vulnerable areas by constructing water harvesting structures, check dams or by adopting various agronomical measures through Governmental schemes, NGOs, stakeholder participation and mass awareness programmes.

1. Dracup, J. A., Lee, K. S. and Paulson, E. G., On the definition of droughts. Water Resour. Res., 1980, 16(2), 297-302.

2. Sun, Y., Solomon, S., Dai, A. and Portmann, R. W., How often does it rain? J. Clim., 2006, 19(6), 916-934.

3. Wilhite, D. A., Drought as a natural hazard: concept and definition. In Drought: a Global Assessment (ed. Wilhite, D. A.), Natural Hazards and Disaster Series, Routledge, UK, 2006, vol. 1, pp. 3-18.
4. Tigkas, D., Vangelis, H. and Tsakiris, G., The drought indices calculator (DrinC). In Proceedings of the 8th International Conference of EWRA: Water Resources Management in an Interdisciplinary and Changing Context, Porto, Portugal, 2013.

5. Fussel, H. M. and Klein, R. J. T., Climate change vulnerability assessments: an evolution of conceptual thinking. Clim. Change, 2006, 75(3), 301-329.

6. Zarafshani, K., Sharafi, L., Azadi, H., Hosseininia, G., DeMaeyer, P. and Witlox, F., Drought vulnerability assessment: the case of wheat farmers in Western Iran. Glob. Planet. Change, 2012, 98, $122-130$.

7. Wilhelmi, O. V. and Wilhite, D. A., Assessing vulnerability to agricultural drought: a Nebraska case study. Nat. Hazards, 2002, $\mathbf{2 5}(1), 37-58$.

8. Lindoso, D. P., Rocha, J. D., Debortoli, N., Parente, I. I., Eiro, F., Bursztyn, M. and Rodrigues-Filho, S., Integrated assessment of smallholder farming's vulnerability to drought in the Brazilian Semi-arid: a case study in Ceara. Clim. Change, 2014, 127(1), 93105.

9. Brenkert, A. L. and Malone, E. L., Modeling vulnerability and resilience to climate change: a case study of India and Indian states. Clim. Change, 2005, 72(1), 57-102.

10. Swain, M. and Swain, M., Vulnerability to agricultural drought in western Orissa: a case study of representative blocks. Agric. Econ. Res. Rev., 2007, 24(1), 47-56.

11. Alcamo, J., Acosta-Michlik, L., Carius, A., Eierdanz, F., Klein, R., Kromker, D. and Tanzler, D., A new approach to quantifying and comparing vulnerability to drought. Reg. Environ. Change, 2008, 8(4), 137-149.

12. Iglesias, A., Moneo, M. and Quiroga, S., Methods for evaluating social vulnerability to drought. In Coping with Drought Risk in Agriculture and Water Supply Systems (eds Iglesias et al.), Adv. Natural Technol. Hazards Res., 2009, 153-159.

13. Pandey, R. P., Pandey, A., Galkate, R. V., Byun, H. R. and Mal, B. C., Integrating hydro-meteorological and physiographic factors for assessment of vulnerability to drought. Water Resour. Manage., 2010, 24(15), 4199-4217.

14. Thomas, T., Jaiswal, R. K., Galkate, R., Nayak, P. C. and Ghosh, N. C., Drought indicators-based integrated assessment of drought vulnerability: a case study of Bundelkhand droughts in central India. Nat. Hazards, 2016, 81(3), 1627-1652.

15. IMD, Manual on hydrometeorology - part I. Climatological tables of observations in India. India Meteorological Department, New Delhi, 1972, pp. 45-69.

16. McKee, T. B., Doesken, N. J. and Kleist, J., The relationship of drought frequency and duration to time scales. Proceedings of the 8th Conference on Applied Climatology, Boston, Am. Meteorol. Soc., 1993, 17(22), 179-183.

17. Sims, A. P., Niyogi, D. S. and Raman, S., Adopting drought indices for estimating soil moisture: a North Carolina case study. Geophys. Res. Lett., 2002, 29(8), 241-244.

18. Thomas, T., Jaiswal, R. K., Nayak, P. C. and Ghosh, N. C., Comprehensive evaluation of the changing drought characteristics in Bundelkhand region of central India. Meteorol. Atmos. Phys., 2014, 127(2), 163-182.

Received 15 October 2017; revised accepted 7 March 2018

doi: $10.18520 /$ cs/v115/i2/338-346 